the drought are favourable. It has definitely broken up in Australia." (Weather forecast, dated November 23, Ig03.)

Writing a year later, November 23rd, 1904, I said: "My weather forecast for last year (published in the Cape Times of November 23, 1903) indicated the expectation of a more or less complete break-up of the drought. This forecast has been fulfilled. In many parts of South Africa, particularly towards the north, the drought has broken, and good seasons were experienced last year. In other parts the rains were insufficient to really break the drought. This was the case in the fertile "conquered territory ' of Orangia, and over wide areas in Cape Colony. In the Transkej drought remains unbroken. It is described as a drought of terrible severity, and one that has stopped all ploughing and killed from 50 to 60 per cent. of the sheep in some of the districts. As was remarked by a correspondent in the Cape Times a few days since,

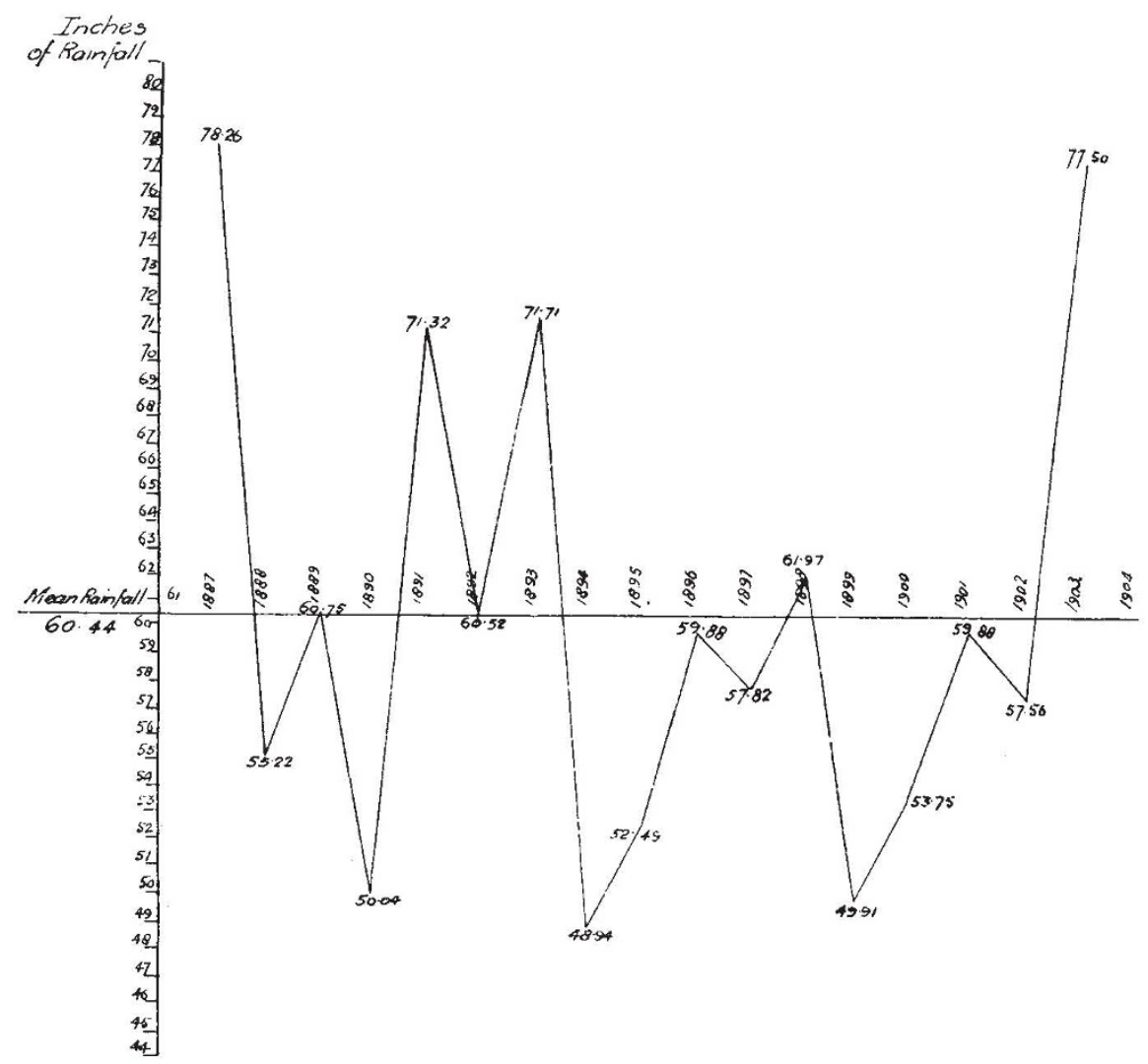

Fic. r.-Rainfall, Evelyn Valley.

'No one not living here has any idea of the terrible condition existing in the Karoo and Eastern Province The springs on most of the farms have utterly disappeared. On one farm in the Cradock district with large lands, orchards, and a water-mill at the junction of two kloofs in the Sneeuwberg, the river beds are as dry as a street; the farmer has sold all his stock, and I actually saw the water for household use brought some distance in a barrel. In former years the water-mill was in constant use for all the surrounding country."

Writing to me recently from Zomba, in British Central Africa, Mr. Clounie, the head of the scientific department, speaking of last summer's rains, says: "The wet season from November to April last has been remarkably good, and crops everywhere have been excellent. I think everything points to the end of the drought and a return to a period of good rains."

As regards the drought further north, the reader may NO. I 84 I, VOL. 7 I] turn to NaTURE of November 3, 1904 (p. 15). I produce the extract for ready reference :-

"Appendix iii. of a report upon the basin of the Upper Nile, with proposals for the improvement of the river by Sir William Garstin, contains an interesting account of the variations of level of Lake Victoria Nyanza contributed by Captain H. G. Lyons, the director of the Survey Department of Egypt. This lake has a water surface of about 68 , 000 square kilometres, and is situated about 1129 metres above sea-level. It is believed to be of shallow depth, and lies for the most part of the year in the region of the equatorial rain and cloud belt, the excess water draining off at the Ripon Falls by the Victoria Nile. After reference to the geology and climate of the region, a brief historical summary is given of the early lake levels as observed by travellers and others visiting or residing by it; this is followed by a detailed study and discussion of the various gauges. Some of the results obtained are as follows:- The annual oscillation of the lake is from 0.30 metre to 0.90 metre. Between 1896 and 1902 there was a fall of $76 \mathrm{~cm}$. in the average level, since followed by a rise of $56 \mathrm{~cm}$. The epochs of high and low levels are given as :- I878, high level; $1880-$ 9o, falling level ; $1892-5$, temporary high level; 1896-1902, falling level; 1903, rising level."

The kernel of this quotation lies in the last six words: it shows the same correspondence with the Indian rainfall figures as the summer rainfall figures of South Africa. D. E. Hutchins.

Cape Town, December 8.

\section{Compulsory Greek at} Cambridge.

SOME years ago a young lady who was studying at Girton came to Bristol to spend a part of her first vacation after "passing the "Little-go." "She had never learnt Greek at school, but had been coached by an elder brother, who was at that time in residence at Cambridge; in about two months she obtained a knowledge of Greek sufficient to meet the requirements of the authorities at Cambridge.

While she was with us we paid a visit to the neighbouring city of Bath, and I directed her attention to the motto which is inscribed on the Roman baths there, viz.:

«

Remembering her recent success in the "Little-go," I jokingly asked her the meaning of this inscription-not imagining for a moment that Cambridge compulsory Greek would be unequal to such an easy task; she was, however, unable to give the meaning of the words; she did

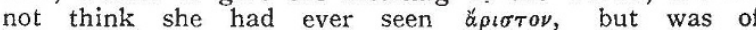
opinion that she had in the course of her reading met the word $\delta \delta \omega \rho$, but did not remember what it meant.

It may be well to add that the lady in question has great linguistic ability, and in due course obtained a good place in the Modern Languages Tripos.

Do our ultra-classical friends really think that compulsory "Greek" of this type is worth preserving?

Merchant Venturers' Technical College, J. WERTHEIMER. Bristol, January 30 